\title{
Ciclo de mejora docente aplicado al estudio del Derecho cambiario: otra manera de enseñar y aprender
}

\section{A classroom improvement cycle applied to the study of the bill of exchange and other payment undertakings: another way to teach and learn}

maría Salomé Lorenzo Camacho

https://orcid.org//0000-0002-3902-8284

Universidad de Sevilla

Departamento de Derecho Mercantil

mslorenzo@us.es

DOI: http://dx.doi.org/10.12795/9788447231003.041

Pp.: 863-884 


\section{Contexto}

El Ciclo de Mejora en el Aula (en adelante, CIMA) que se presenta se desarrolló en la asignatura Derecho Mercantil II, de carácter obligatoria y anual, que se imparte en el cuarto curso del Grado en Derecho. En concreto, se aplicó a un grupo que cuenta con 54 alumnos matriculados, de los cuales 15 son repetidores.

Respecto a la asistencia a las sesiones, hay que tener en cuenta las singularidades vividas durante el curso 2020/2021, lo que condujo a que la aplicación del CIMA se llevase a cabo en dos escenarios distintos: las cuatro primeras sesiones se desarrollaron en un contexto de semipresencialidad, en el que los alumnos estaban organizados en tres grupos que asistían a las clases presenciales en turnos rotatorios: cada semana, asistía uno de los grupos a clase, mientras que los alumnos de los otros dos grupos seguían la sesión de forma sincrona a través de Blackboard Collaborate Ultra. En esta etapa, el número de estudiantes asistentes a la clase presencial fue ciertamente reducido (10-12 alumnos), mientras que de forma online el número de participantes en la sesión virtual se encontraba generalmente alrededor de los 25-35 alumnos. Las tres últimas sesiones se llevaron a cabo íntegramente a través de clases online (sesiones síncronas) dada la suspensión de la actividad docente presencial. En este otro contexto, asistieron con regularidad en torno a 40 alumnos.

El CIMA se desarrolló los días 21, 27, y 28 de octubre; 3 , 4, 10 y 11 de noviembre, en siete sesiones de una hora, según el horario habitual de la asignatura.

Ciclos de Mejora en el Aula (2020). Experiencias de Innovación Docente de la US Esta obra se distribuye con la licencia Creative Commons 


\section{Diseño del Ciclo de Mejora en el Aula}

A la hora de diseñar el CIMA, se elaboró el mapa de contenidos relativos al tema que trataríamos en clase y que abarcaría las siete horas en las que el mismo se iba a implementar (títulos cambiarios y crisis cambiarias). En línea con ello, se representó gráficamente el modelo metodológico posible, se diseñó la secuencia de actividades a realizar y un cuestionario inicial/final, que se utilizó para evaluar los conocimientos previos del alumnado y sus modelos mentales en relación con los contenidos que trataríamos en el CIMA.

\section{Mapa de contenidos}

El mapa de contenidos se representa en la Figura 1. Los contenidos en los que se centra son los relativos a la letra de cambio y a las posibles acciones cambiarias y sus consecuencias. Se utilizan cuatro preguntas/interrogantes que dirigen y sirven de soporte para guiar el proceso de aprendizaje de los alumnos. Comenzamos preguntándonos cuál es la función económica de los títulos cambiarios, que servirá para trabajar el contenido conceptual del régimen de circulación y pago de los mismos.

A continuación, nos planteamos cómo se cumplimentan los títulos cambiarios, lo que nos permite detenernos en los contenidos conceptuales relativos a los elementos formales del título, y que conecta con el contenido procedimental relativo al libramiento o emisión. En esta parte, se pone de manifiesto que no sólo es importante "saber" (conocer cada uno de los elementos que conforman estos títulos) sino también "saber hacer", o lo que es lo mismo, saber cumplimentarlos a partir de problemas prácticos en los que se describen, por ejemplo, relaciones jurídicas que las partes deciden trasladar a un título cambiario (García, Porlán y Navarro, 2017).

Ciclos de Mejora en el Aula (2020). Experiencias de Innovación Docente de la US Esta obra se distribuye con la licencia Creative Commons 
El siguiente paso pasa por determinar qué ocurrirá cuando, llegado el vencimiento, el título resulte impagado (tercer interrogante del mapa), que enlaza con los contenidos conceptuales de las crisis cambiarias y las posibles acciones a ejercitar, así como con el tratamiento procesal de la disciplina.

Para finalizar, con el cuarto interrogante se persigue conocer cuál es el presente y futuro de los títulos cambiarios, y servirá para trabajar el contenido actitudinal de la materia: valorar qué efectos está teniendo la desmaterialización de los títulos (crisis del soporte papel) y preguntarse si el marco normativo vigente en España está en coherencia con la actualidad o si, por el contrario, aún no se ha dado el paso de reconocer legalmente la emisión de títulos cambiarios en forma electrónica. En este mismo sentido, se planteará el debate en torno a la consideración de los valores digitales como títulos-valores.

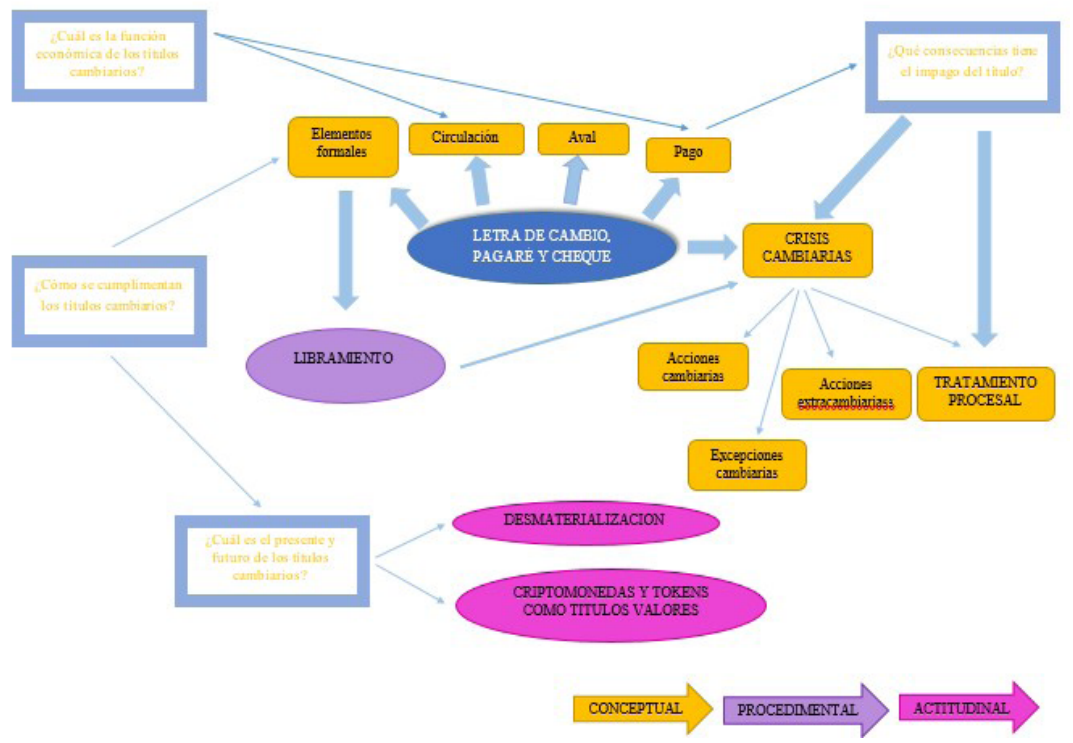

Figura 1. Mapa de contenidos.

Ciclos de Mejora en el Aula (2020). Experiencias de Innovación Docente de la US Esta obra se distribuye con la licencia Creative Commons 


\section{Modelo metodológico y secuencia de actividades}

El modelo metodológico que guio esta experiencia tiene las siguientes fases (Figura 2):

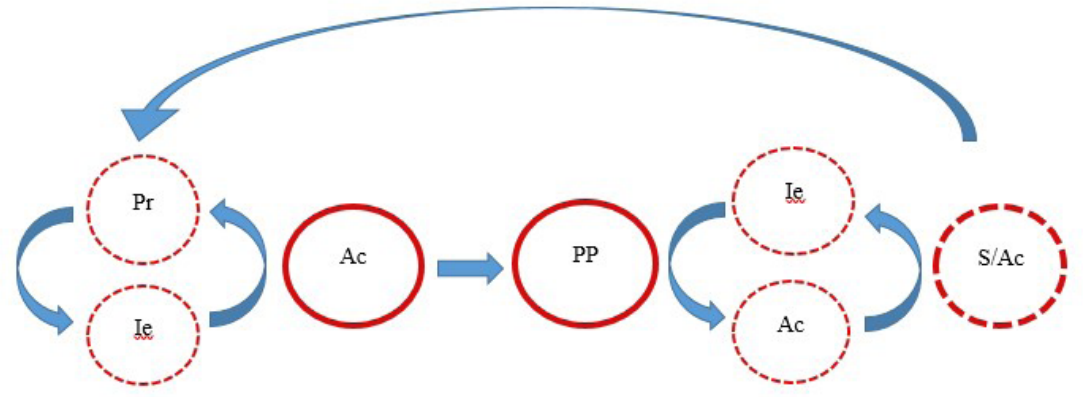

Figura 2. Modelo metodológico posible.

El CIMA se inicia con un cuestionario inicial o secuencia de preguntas/interrogantes al alumnado ( $\mathrm{Pr}$ ), relacionadas con los contenidos que serán objeto de tratamiento en las sesiones, y seguido de la exposición de las ideas o modelos mentales de los que parten sobre dicha materia (Ie). Las dos fases anteriores sirven para abordar una de las fases nucleares del CIMA, que son las actividades de contraste (Ac), en las que se plantearán principalmente actividades con las que los alumnos se cuestionen sus ideas iniciales y puedan reconstruirlas (lecturas orientativas de normas jurídicas, búsqueda de materiales a través de recursos electrónicos de la Biblioteca de la Universidad de Sevilla -resoluciones judiciales, artículos doctrinales, formularios en Westlaw, Aranzadi Doctrinal, Tirant online, Biblioteca Tirant, La Ley Digital- y entradas en blogs jurídicos).

La reconstrucción de sus ideas iniciales a partir de las actividades de contraste señaladas (Ac) posibilita que, a continuación, se pueda plantear la segunda de las fases más significativas del CIMA: el estudio y resolución de problemas prácticos reales (PP). Esta actividad permite, de nuevo, que el alumnado exprese sus ideas y las

Ciclos de Mejora en el Aula (2020). Experiencias de Innovación Docente de la US Esta obra se distribuye con la licencia Creative Commons 
conclusiones alcanzadas sobre los problemas planteados (le), así como que la profesora reorganice/reconstruya las soluciones alcanzadas (Ac) y, a continuación, sintetice las ideas más importantes ( $\mathrm{S} / \mathrm{Ac}$ ), retomando finalmente las preguntas/interrogantes iniciales con los que se comenzó el CIMA.

Para la aplicación de este modelo metodológico se prepararon 18 actividades, que no se representan íntegramente por falta de espacio.

Como ejemplo, en la Tabla 1 se muestra la secuencia de actividades prevista para las sesiones 1 a 4.

Tabla 1. Secuencia de actividades

\begin{tabular}{|c|c|c|c|c|}
\hline \multicolumn{5}{|c|}{ Sesión 1 (1 hora) } \\
\hline № ACT. & ACTIVIDAD & DESCRIPCIÓN & FASE & TIEMPO \\
\hline 1 & $\begin{array}{l}\text { Presentación } \\
\text { y cuestionario } \\
\text { inicial: “QQué } \\
\text { consecuencias } \\
\text { tiene el impago } \\
\text { de un título } \\
\text { cambiario?" }\end{array}$ & $\begin{array}{l}\text { Después del saludo } \\
\text { inicial y de explicar } \\
\text { la actividad, los } \\
\text { alumnos responden } \\
\text { individualmente a un } \\
\text { cuestionario inicial. } \\
\text { Preguntas en forma de } \\
\text { problemas prácticos } \\
\text { reales, aunque con } \\
\text { lenguaje más coloquial. }\end{array}$ & $\begin{array}{l}\operatorname{Pr} \text { (problemas } \\
\text { de interés). }\end{array}$ & $35^{\prime}$ \\
\hline 2 & $\begin{array}{l}\text { Puesta en común } \\
\text { del cuestionario } \\
\text { inicial. }\end{array}$ & $\begin{array}{l}\text { Se invita a los } \\
\text { alumnos a compartir } \\
\text { las respuestas al } \\
\text { cuestionario inicial. }\end{array}$ & $\begin{array}{l}\text { le (ideas de los } \\
\text { estudiantes } \\
\text { respecto de } \\
\text { las preguntas/ } \\
\text { problemas } \\
\text { planteados) }\end{array}$ & $15^{\prime}$ \\
\hline 3 & $\begin{array}{l}\text { Conclusiones de } \\
\text { la sesión. }\end{array}$ & $\begin{array}{l}\text { Recapitulación sobre } \\
\text { la tarea realizada y } \\
\text { orientaciones para la } \\
\text { próxima clase. }\end{array}$ & Sintesis (S). & $10^{-}$ \\
\hline
\end{tabular}

Ciclos de Mejora en el Aula (2020). Experiencias de Innovación Docente de la US Esta obra se distribuye con la licencia Creative Commons 


\begin{tabular}{|c|c|c|c|c|}
\hline \multicolumn{5}{|c|}{ Sesión 2 (1 hora) } \\
\hline № ACT. & ACTIVIDAD & $\begin{array}{l}\text { DESCRIPCIÓN Y } \\
\text { CONTENIDO }\end{array}$ & FASE & TIEMPO \\
\hline 4 & $\begin{array}{l}\text { Presentación } \\
\text { y Problemas } \\
\text { prácticos reales: } \\
\text { ¿Cómo traslado } \\
\text { la relación } \\
\text { jurídica principal } \\
\text { a un título } \\
\text { cambiario?" }\end{array}$ & $\begin{array}{l}\text { Después del saludo } \\
\text { inicial y de explicar la } \\
\text { actividad, los alumnos } \\
\text { cumplimentan títulos } \\
\text { cambiarios a partir de } \\
\text { problemas prácticos } \\
\text { reales. Para mantener } \\
\text { el hilo conductor del } \\
\text { CIMA, hacemos uso de } \\
\text { los problemas prácticos } \\
\text { del cuestionario inicial. } \\
\text { CONTENIDO: Los } \\
\text { elementos formales. El } \\
\text { libramiento. }\end{array}$ & $A C / P P$ & $30^{-}$ \\
\hline 5 & $\begin{array}{l}\text { Exposición por } \\
\text { los alumnos } \\
\text { de los títulos } \\
\text { cambiarios } \\
\text { cumplimentados. }\end{array}$ & $\begin{array}{l}\text { A modo de ronda, los } \\
\text { alumnos van indicando } \\
\text { dónde han ubicado en } \\
\text { las letras de cambio, } \\
\text { pagarés y cheques } \\
\text { a los sujetos de los } \\
\text { problemas prácticos } \\
\text { (librador, librado, } \\
\text { firmante, tomador, } \\
\text { endosante, avalista...). } \\
\text { conTENIDO: Los } \\
\text { elementos formales. El } \\
\text { libramiento. }\end{array}$ & $\begin{array}{l}\text { le (ideas de los } \\
\text { estudiantes } \\
\text { respecto de } \\
\text { las preguntas/ } \\
\text { problemas } \\
\text { planteados). }\end{array}$ & $20^{-}$ \\
\hline 6 & $\begin{array}{l}\text { Cierre de la } \\
\text { sesión. }\end{array}$ & $\begin{array}{l}\text { Recapitulación sobre } \\
\text { la tarea realizada y } \\
\text { orientaciones para la } \\
\text { próxima clase. }\end{array}$ & Sintesis (S). & $10^{-}$ \\
\hline \multicolumn{5}{|c|}{ Sesión 3 (1 hora) } \\
\hline № ACT. & ACTIVIDAD & $\begin{array}{l}\text { DESCRIPCIÓN Y } \\
\text { CONTENIDO }\end{array}$ & FASE & TIEMPO \\
\hline
\end{tabular}

Ciclos de Mejora en el Aula (2020). Experiencias de Innovación Docente de la US Esta obra se distribuye con la licencia Creative Commons Reconocimiento-NoComercial-SinObraDerivada Internacional (CC BY-NC-ND 4.0.) 


\begin{tabular}{|c|c|c|c|c|}
\hline 7 & $\begin{array}{l}\text { Presentación y } \\
\text { desarrollo de } \\
\text { nueva actividad: } \\
\text { ¿Cuál es el } \\
\text { régimen jurídico } \\
\text { de las crisis } \\
\text { cambiarias? } \\
\text { ¿Y qué otras } \\
\text { fuentes } \\
\text { (doctrinales/ } \\
\text { juris- } \\
\text { prudenciales) lo } \\
\text { complementan?” } \\
\text { ¿Y cuál es el } \\
\text { presente y futuro } \\
\text { de los títulos } \\
\text { cambiarios?” }\end{array}$ & $\begin{array}{l}\text { Después del saludo } \\
\text { inicial y de explicar la } \\
\text { nueva actividad, los } \\
\text { alumnos comienzan } \\
\text { a trabajar a partir de } \\
\text { la "hoja de trabajo" } \\
\text { diseñada por la } \\
\text { profesora. Se pretende } \\
\text { que mejoren en la } \\
\text { búsqueda autónoma de } \\
\text { recursos (legislativos, } \\
\text { doctrinales y } \\
\text { jurisprudenciales), } \\
\text { que distingan la } \\
\text { información relevante } \\
\text { de la secundaria, y que } \\
\text { hagan el ejercicio de } \\
\text { interpretarlas. } \\
\text { conTENIDO: } \\
\text { Libramiento. Crisis } \\
\text { cambiarias y } \\
\text { tratamiento procesal. } \\
\text { Presente y futuro de los } \\
\text { títulos cambiarios. }\end{array}$ & $A C$ & $50^{-}$ \\
\hline 8 & $\begin{array}{l}\text { Cierre de la } \\
\text { sesión. }\end{array}$ & $\begin{array}{l}\text { Los estudiantes ponen } \\
\text { en común en qué } \\
\text { punto se encuentran de } \\
\text { la tarea, y la profesora } \\
\text { adelanta a qué nos } \\
\text { dedicaremos en la } \\
\text { próxima sesión. }\end{array}$ & Sintesis (S). & $10^{-}$ \\
\hline \multicolumn{5}{|c|}{ Sesión 4 (1 hora) } \\
\hline № ACT. & ACTIVIDAD & DESCRIPCIÓN & FASE & TIEMPO \\
\hline 9 & $\begin{array}{l}\text { Presentación y } \\
\text { puesta en común } \\
\text { de materiales y } \\
\text { recursos. }\end{array}$ & $\begin{array}{l}\text { Los estudiantes van } \\
\text { planteando al profesor } \\
\text { y al resto de la clase los } \\
\text { materiales y recursos } \\
\text { que han seleccionado. } \\
\text { Se plantean las dudas y } \\
\text { las cuestiones jurídicas } \\
\text { más complejas que han } \\
\text { observado. }\end{array}$ & $\begin{array}{l}\text { le (ideas de los } \\
\text { estudiantes). }\end{array}$ & $35^{\prime}$ \\
\hline
\end{tabular}

Ciclos de Mejora en el Aula (2020). Experiencias de Innovación Docente de la US Esta obra se distribuye con la licencia Creative Commons 


\begin{tabular}{|c|c|c|c|c|}
\hline 10 & $\begin{array}{l}\text { Régimen jurídico } \\
\text { de las acciones } \\
\text { cambiarias y } \\
\text { extracambiarias } \\
\text { en caso } \\
\text { de impago } \\
\text { del título. } \\
\text { Tratamiento } \\
\text { procesal. }\end{array}$ & $\begin{array}{l}\text { La profesora, a partir } \\
\text { de las ideas de los } \\
\text { alumnos y de las } \\
\text { dudas planteadas, } \\
\text { "reorganiza/ } \\
\text { reconstruye" los } \\
\text { planteamientos de los } \\
\text { estudiantes y expone } \\
\text { el régimen legal de las } \\
\text { acciones cambiarias. } \\
\text { conTENIDO: } \\
\text { Libramiento. Crisis } \\
\text { cambiarias y } \\
\text { tratamiento procesal. } \\
\text { Presente y futuro de los } \\
\text { títulos cambiarios. }\end{array}$ & $\mathrm{AC} / \mathrm{T}$ & $15^{\prime}$ \\
\hline 11 & $\begin{array}{l}\text { Cierre de la } \\
\text { sesión. }\end{array}$ & $\begin{array}{l}\text { Se realiza una breve } \\
\text { recapitulación y } \\
\text { la profesora da } \\
\text { orientaciones sobre la } \\
\text { próxima sesión. }\end{array}$ & Sintesis (S). & $10^{-}$ \\
\hline
\end{tabular}

\section{Cuestionario inicial y final}

Para explorar los modelos mentales iniciales de los estudiantes sobre los problemas planteados en el mapa de contenidos, se elaboró un cuestionario en el que se planteaban situaciones que permitieran conseguir la atención de los alumnos (Bain, 2007), y que evidenciara sus formas de razonar y las ideas que desarrollaban ante problemas relevantes de la materia (Rivero y Porlán, 2017).

Tomando como referencia dos problemas prácticos, el cuestionario estaba formado por cuatro preguntas, que se reproducen a continuación:

Cementos Andalucía, S. L. vendió a Suroeste Construcciones, S. A. una partida de mortero seco y hormigón por valor de $20000 €$. Se acordó aplazar el pago en seis meses, emitiéndose una letra de cambio cuyo pago fue garantizado mediante aval por Hispana de Ingeniería, S. A.

Ciclos de Mejora en el Aula (2020). Experiencias de Innovación Docente de la US Esta obra se distribuye con la licencia Creative Commons 
1. ¿Con qué finalidad piensas que Suroeste Construcciones, S. A. y Cementos Andalucía, S. L. trasladan dicha relación a una la letra de cambio?

El 1 de julio, Andrea Aranda compró a Inforhelp, S. A. diez equipos informáticos, por un valor total de $8800 €$, emitiéndose por Andrea Aranda una letra de cambio por dicho importe, que fue avalada por Matías Méndez, y quedando aplazado su pago hasta el 1 de octubre. El 15 de julio, el tomador endosó la letra a Reparaciones Informáticas, S. L. y, llegado su vencimiento, el título resultó impagado.

2. ¿Contra quién o quiénes podrá reclamar el pago el tenedor legítimo de la letra de cambio?

3. ¿Qué acciones judiciales podrían ejercitarse?

4. ¿Qué podría reclamarse?

\section{Aplicación del Ciclo de Mejora en el Aula}

\section{Relato de las sesiones}

Comencé las sesiones del CIMA el miércoles 21 de octubre. Intenté llevar todo preparado en relación con el cuestionario inicial que les iba a pasar: unos dias antes, informé por la plataforma que debían traer a clase ordenador portátil o tablet para realizar la actividad. Cuando llegué al aula comprobé, como me habían comentado algunos compañeros, que la situación de semipresencialidad generaba una sensación extraña, como todo lo nuevo. Efectivamente, no sólo era eso, sino también la organización de todo el material (proyector, cámara, enfoque, sesión de Blackboard, micrófono, limpieza...) y la coordinación entre los alumnos que estaban en el aula y los que estaban en casa. A esta primera sesión asistieron presencialmente 8 alumnos. Como ya habíamos tenido hacía unas semanas una sesión de presentación de los profesores y

Ciclos de Mejora en el Aula (2020). Experiencias de Innovación Docente de la US Esta obra se distribuye con la licencia Creative Commons 
de la asignatura, sólo saludé a los alumnos, y comencé a presentar el cuestionario inicial: “Qué consecuencias tiene el impago de un título cambiario?". Mientras les iba comentando la tarea, fueron accediendo a la plataforma y localizando el cuestionario. Les reiteré que lo contestaran conforme a los conocimientos que tenían en ese momento. Mientras los alumnos hacían el cuestionario, no puedo negar que no paraba de preguntarme a mí misma si llegaría a funcionar el CIMA.

Como siempre ocurre cuando hacen tareas en clase, se suele tardar más en su finalización que lo que inicialmente tenía programado: fueron prácticamente cerca de 45 minutos lo que emplearon, ya que no sólo tenía a los 8 alumnos presenciales, sino también a los de la sesión online (26). Una vez finalizado, les invité a que compartieran sus respuestas y sensaciones durante la actividad, y observé que la mayor preocupación del alumnado era el hecho de haber contestado el cuestionario sin conocer aún la solución jurídica a las cuestiones planteadas, por sentido común. Poco a poco se animaron a participar, también los que seguían la clase online, manifestando que, con el ejercicio habían comprobado que aún no tenían consolidados determinados conceptos jurídicos previos del mismo Tema 9.

Al hilo de lo anterior, me preguntaron si se podría hacer alguna actividad práctica al respecto. En ese momento, ya comienzo a darme cuenta de que he planteado algunas actividades para el día siguiente que no podré realizar dado el punto de partida que tienen los alumnos por las dificultades que me comentan. Intenté no pensar demasiado en ese momento sobre dicho "contratiempo" y directamente les propuse que el próximo día hiciésemos ejercicios de cumplimentación de letra de cambio. Acordamos que en la próxima clase trasladarían los datos de los problemas prácticos del cuestionario inicial a títulos cambiarios. Me despedí recomendándoles que llevasen a la clase siguiente letras de cambio impresas, y la Ley Cambiaria y del Cheque.

Ciclos de Mejora en el Aula (2020). Experiencias de Innovación Docente de la US Esta obra se distribuye con la licencia Creative Commons 
Al salir del aula, me sentí en parte insegura con las tareas que había diseñado. Tenía que remodelar la secuencia de actividades y preparar para el próximo día una tarea que no tenía planificada ni hecha.

La segunda sesión del CIMA 2 tuvo lugar el martes 27 de octubre. Comencé explicándoles que dedicaríamos la clase a problemas prácticos reales, más concretamente, a trasladar relaciones jurídicas (p. e. compraventas) a letras de cambio, para lo que proyecté el título de la sesión: ¿Cómo traslado la relación jurídica principal a un título cambiario? Como tenía alumnos en clase (10) y en la sesión virtual (33), necesité más tiempo del que tenía previsto para explicarles cómo tenían que realizar la actividad. Les expliqué que tenían los problemas prácticos como una actividad en la plataforma, que eran los mismos que les había planteado en el cuestionario inicial, y que, a partir de ahí, tenían que comenzar a rellenar los impresos. Los alumnos que estaban en el aula se implicaron en la tarea, cumplimentando los títulos a partir de las indicaciones de la propia Ley. Sólo una alumna me planteó dudas a la hora de rellenar las letras, pero empleé su pregunta para implicar al resto en la duda, interviniendo otros dos alumnos más. Lo que sí observé es que, aunque no son muy participativos, me pedían que les confirmase que "iban bien" en el ejercicio.

Cuando quedaban 15 minutos para terminar la sesión me di cuenta de que aún tenían que exponer ellos sus soluciones. Les pedí que comenzasen a comentar cómo habían cumplimentado las letras y que, a modo de ronda, fuesen indicando dónde habían ubicado en los impresos de letra de cambio a los sujetos de los problemas prácticos (librador, librado, firmante, tomador, endosante, avalista...). Es cierto que en esta otra tarea sí intervinieron más, pero tuve que ser yo la que iba dirigiéndolos, no percibí una participación "espontánea" por parte de ellos. Al 
intervenir, la mayoría de los alumnos tenían problemas en los mismos puntos controvertidos. Aproveché que algunos decían la respuesta correcta para que, cuando otros por chat indicaban que no les había quedado claro, fueran ellos quienes se explicaran y resolvieran las dudas. Para finalizar, hice una recapitulación de la tarea, y adelanté brevemente a qué dedicaríamos la siguiente sesión. Salí del aula más animada que el primer día, pues el diseño de la sesión sí había funcionado.

La tercera sesión del CIMA 2 tuvo lugar el miércoles 28 de octubre. Comencé con el saludo inicial y presenté en pantalla el nombre de la actividad de la sesión: ¿Cuál es el régimen jurídico de las crisis cambiarias? ¿Y qué otras fuentes (doctrinales/ jurisprudenciales) lo complementan? Como les expliqué, durante la mañana había subido a la plataforma una "hoja de trabajo". En la misma, les daba un listado de recursos y las posibles búsquedas que podían realizar, relacionadas con los contenidos de la sesión. Diez minutos después, los alumnos que estaban en la clase (10) comenzaron la actividad, pero, aunque yo les indiqué lo que tenían que hacer y además contaban con la "hoja de trabajo", me surgió la duda de si verdaderamente los alumnos que estaban desde casa (32), o al menos todos ellos, se encontraban igual de implicados. Les indiqué varias veces que me fueran comentando las dudas o consultas que tuvieran, y me planteé si debería haber incorporado algunas actividades, o al menos esta, en grupo, pero es algo en lo que, quizá, tengo "resistencia al cambio", manteniendo la idea de que el trabajo de un jurista es un proceso intelectual individual. No obstante, y visto en el aula cómo la desarrollaron, me di cuenta de que la búsqueda de recursos sí hubiera funcionado en grupo. A las 18.50 h. les pedí que pusieran en común hasta dónde habían avanzado. Intenté hacer una recapitulación de los recursos básicos que necesitarían para las próximas sesiones y me despedí de ellos hasta el próximo martes. Me sentí un poco acelerada al terminar la sesión, y me planteé

Ciclos de Mejora en el Aula (2020). Experiencias de Innovación Docente de la US Esta obra se distribuye con la licencia Creative Commons 
si verdaderamente estaba haciendo todo lo posible por lograr una mayor interacción del alumnado. Creo que, por mi experiencia docente hasta el momento, inconscientemente, trato de redirigirlos y, con ello, no les dejo a veces margen para que sean ellos quienes formen parte activamente en su proceso de aprendizaje.

La cuarta sesión del CIMA 2 se desarrolló el día 3 de noviembre. Volvíamos después de un puente, y se notó en la menor asistencia del grupo al que le tocaba asistir presencialmente esa semana (7 alumnos). En la sesión virtual se mantuvo el número de alumnos habitual (30). En esta sesión nos ocupábamos de realizar la puesta en común de los materiales y recursos que habían buscado en la clase anterior. Como es habitual en los alumnos, les costó comenzar a hablar. En el mismo momento que observé que se resistían a intervenir, les planteé una pregunta, no como yo las hacía siempre (¿qué habéis encontrado?) sino al revés. Les pregunté directamente: ¿no habéis encontrado ni utilizado ningún recurso?, ¿absolutamente nada? Logré el efecto que quería, que demostrasen que efectivamente sí lo habían hecho. Poco a poco comenzaron a intervenir, y procuré ir enlazando las intervenciones, las de los alumnos que estaban en casa con las de los alumnos que estaban en clase.

Dedicamos el resto de la sesión a tratar los contenidos que veníamos trabajando (esto es, el régimen jurídico de las acciones cambiarias y extra-cambiarias en caso de impago del título, y tratamiento procesal) desde otra perspectiva. En concreto, a partir de las ideas que expusieron los alumnos, traté de reorganizar o reconstruir los planteamientos de los estudiantes y exponer el régimen legal de las acciones cambiarias. He de reconocer que, como era una actividad de transmisión directa de contenidos (teórica), me sentí en lo que podría llamar mi "zona de confort docente". Esta vez me pareció, además, que mi exposición 
era mucho más enriquecedora para ellos, en el sentido de que estaba construida a partir de lo que habían trabajado previamente. Después de 10-12 minutos, me despido de la clase, indicándoles que el próximo día volveremos a trabajar problemas prácticos reales.

A la quinta sesión del CIMA, realizada el 4 de noviembre, asistieron 7 alumnos de forma presencial y 35 a través de la sesión online. Llegué animada en el sentido de que la actividad de la sesión iba encaminada a trabajar problemas prácticos reales, que tenían un nivel superior a los que habíamos visto en la tercera sesión. Tras preparar los materiales, presenté el título de la sesión: ¿Qué soluciones legales podemos dar a estas situaciones de impago de títulos cambiarios? ¿A quién se puede reclamar? ¿Qué cantidades? ¿Y en qué plazos? Durante la mañana había subido a la plataforma una "hoja de trabajo" que contaba con tres problemas prácticos. Les expliqué que tenían que acceder a la misma, y que el objetivo de la sesión era que, a partir de los recursos que habíamos venido trabajando, dieran solución a las controversias jurídicas que se planteaban. Les dije que estaría todo el tiempo con ellos para lo que necesitasen, como en sesiones anteriores. No obstante, este día sí me ocurrió un incidente: cuando expliqué la tarea, vi que en el chat un alumno escribió No por favor..., y directamente abandonó la sesión. Procuré que los demás mantuviesen el interés y no les afectase. Esa actitud me hizo pensar que, a lo mejor, debía comenzar a recompensarles las actividades y puntuarlas, más allá del cuestionario, sobre todo la de la sesión del día, que eran los problemas prácticos más importantes del CIMA. El resto de la sesión se desarrolló sin más contratiempos. Para finalizar, sinteticé los problemas prácticos, y expuse las principales consultas y dudas que fueron realizándose en la sesión. Me fui del aula un poco desmotivada por el incidente del alumno, dado que había trabajado mucho en la preparación de las sesiones, y la semipresencialidad dificultaba en mayor medida la creación o aproximación a un buen entorno para el aprendizaje.

Ciclos de Mejora en el Aula (2020). Experiencias de Innovación Docente de la US Esta obra se distribuye con la licencia Creative Commons 
La sexta sesión se llevó a cabo el día 10 de noviembre. Supuso un cambio de nuevo en el modelo de docencia, pues con las nuevas restricciones por la crisis COVID-19, ese mismo día comenzaba la suspensión de la actividad docente presencial y el paso a las clases virtuales. Me preocupó que tuviéramos que terminar de aplicar el CIMA de esta forma, sobre todo, teniendo en cuenta que las actividades estaban diseñadas para lograr mayor interacción, y en las sesiones virtuales se pierde la cercanía. Asistieron a la sesión 41 alumnos. El objetivo de la sesión era que, de forma oral, fueran exponiendo los problemas prácticos que habían trabajado, el proceso seguido para resolverlos, los recursos empleados y las soluciones alcanzadas (puesta en común de los resultados). Me sorprendió el buen trabajo que hicieron algunos alumnos, dos de ellos repetidores. No solicité que me enviasen la tarea por escrito, pero dichos estudiantes me enviaron unos informes que me sorprendieron por la mejora que suponían en su redacción y en la resolución que daban a las controversias planteadas. Gracias a ello se logró más participación: los alumnos que enviaron los informes se lanzaron más seguros a ir planteando sus soluciones, y el resto de compañeros comenzó igualmente a soltarse. Se creó, en parte, lo que estaba persiguiendo alcanzar con las sesiones (un espacio de interacción de los alumnos), aunque es cierto que yo continué redirigiendo y organizando las intervenciones, así como haciendo aclaraciones cuando se llegaba a cuestiones jurídicas de mayor complejidad. Dedicamos 45 minutos a la exposición de los alumnos, y a continuación empleé otros 10 minutos para sintetizar las ideas más importantes. Cerré la sesión más satisfecha que en la clase previa, pues pude percibir mayor implicación, y la evolución positiva que estaban experimentando (más seguridad, mejor expresión oral y más corrección en el empleo de terminología jurídica).

Ciclos de Mejora en el Aula (2020). Experiencias de Innovación Docente de la US Esta obra se distribuye con la licencia Creative Commons 
La séptima y última sesión del CIMA 2, celebrada el día 11 de noviembre, la dedicamos integra al cuestionario inicial de la materia. Comencé saludando a los asistentes y explicándoles que volvíamos al punto de inicio, dado que la actividad del día sería responder, a partir del cuestionario, la siguiente pregunta: “¿Qué consecuencias tiene el impago de un título cambiario?". Los alumnos comenzaron a acceder al cuestionario en la plataforma para responderlo, y para el desarrollo de la actividad se emplearon unos 30 minutos. Una vez que fueron finalizando, les invité a que compartieran sus impresiones sobre la tarea, y sobre las sesiones que habíamos desarrollado en los últimos días. Algunos hicieron comentarios en un tono divertido ("espero que no esté peor que el primer cuestionario", "a ver si vamos a empeorar las cosas"), mientras que otros estaban de acuerdo en que se habían encontrado en condiciones de dar respuestas "como lo que hemos hecho estos días", o "con más conocimientos sobre la materia". Me despedí agradeciendo a todos su participación y su implicación. Reconozco que, a pesar los cambios en los escenarios de docencia que hemos sufrido, el grupo ha mostrado una buena actitud en las sesiones del CIMA, siendo pacientes (pues no sólo tienen mi asignatura y mis tareas, sino muchas más obligaciones) y adaptándose a los cambios también en mi forma de dar clase.

\section{Evaluación del aprendizaje de los estudiantes}

La evaluación de los conocimientos previos del alumnado y de sus modelos mentales en relación con los contenidos del CIMA se realizó a través del cuestionario inicial, que fue la primera actividad de la secuencia, siendo respondido en clase por 43 alumnos. El mismo cuestionario fue el utilizado en la séptima sesión, siendo respondido en una clase virtual (sesión síncrona) por 39 estudiantes.

Ciclos de Mejora en el Aula (2020). Experiencias de Innovación Docente de la US Esta obra se distribuye con la licencia Creative Commons 
El análisis de las respuestas de los estudiantes ha permitido identificar los diferentes modelos de respuestas, que se muestran a continuación en la Tabla 2. A través de estos modelos de respuestas, se ha logrado identificar los principales obstáculos de aprendizaje de los contenidos del CIMA.

Tabla 2. Definición de los modelos de respuesta.

\begin{tabular}{|c|c|c|c|c|}
\hline & PREGUNTA 1 & PREGUNTA 2 & PREGUNTA 3 & PREGUNTA 4 \\
\hline$E$ & & Sin contestar & Sin contestar & Sin contestar \\
\hline D & Sin contestar & $\begin{array}{l}\text { Referencia } \\
\text { a sujetos } \\
\text { cambiarios de } \\
\text { forma errónea }\end{array}$ & $\begin{array}{l}\text { Referencia a una } \\
\text { reclamación de } \\
\text { cantidad }\end{array}$ & $\begin{array}{l}\text { El importe } \\
\text { de la letra } \\
\text { exclusivamente }\end{array}$ \\
\hline C & $\begin{array}{l}\text { Garantizar el } \\
\text { pago }\end{array}$ & $\begin{array}{l}\text { Referencia de } \\
\text { forma genérica } \\
\text { a los "obligados } \\
\text { cambiarios" }\end{array}$ & $\begin{array}{l}\text { Referencia } \\
\text { genérica a } \\
\text { las acciones } \\
\text { cambiarias }\end{array}$ & $\begin{array}{l}\text { El importe de } \\
\text { la letra y una } \\
\text { indemnización }\end{array}$ \\
\hline B & $\begin{array}{l}\text { Poner en } \\
\text { circulación } \\
\text { el crédito; } \\
\text { dar crédito al } \\
\text { deudor; reforzar } \\
\text { jurídicamente } \\
\text { la relación }\end{array}$ & $\begin{array}{l}\text { Identifican } \\
\text { al librado- } \\
\text { aceptante y } \\
\text { a su avalista, } \\
\text { pero no al } \\
\text { endosante }\end{array}$ & $\begin{array}{l}\text { Referencia a la } \\
\text { acción cambiaria } \\
\text { directa y a la } \\
\text { acción de regreso }\end{array}$ & $\begin{array}{l}\text { El importe de la } \\
\text { letra, intereses } \\
\text { y otros gastos }\end{array}$ \\
\hline A & $\begin{array}{l}\text { Al acreedor le } \\
\text { permite poner } \\
\text { en circulación } \\
\text { el crédito; } \\
\text { y al deudor } \\
\text { le concede } \\
\text { crédito. Se } \\
\text { otorga mayor } \\
\text { seguridad } \\
\text { jurídica porque } \\
\text { el título lleva } \\
\text { aparejada } \\
\text { ejecución }\end{array}$ & $\begin{array}{l}\text { Identifican } \\
\text { a todos los } \\
\text { sujetos del } \\
\text { caso práctico a } \\
\text { los que podrá } \\
\text { reclamarse el } \\
\text { importe de la } \\
\text { letra }\end{array}$ & $\begin{array}{l}\text { Referencia a } \\
\text { las acciones } \\
\text { cambiarias } \\
\text { (directa y de } \\
\text { regreso) y a las } \\
\text { acciones extra- } \\
\text { cambiarias } \\
\text { (causal y de } \\
\text { enriquecimiento } \\
\text { injusto) }\end{array}$ & $\begin{array}{l}\text { El importe } \\
\text { de la letra, } \\
\text { los intereses } \\
\text { pactados, los } \\
\text { réditos de } \\
\text { la cantidad } \\
\text { anterior } \\
\text { devengados } \\
\text { desde el } \\
\text { vencimiento } \\
\text { y los demás } \\
\text { gastos }\end{array}$ \\
\hline
\end{tabular}

Ciclos de Mejora en el Aula (2020). Experiencias de Innovación Docente de la US Esta obra se distribuye con la licencia Creative Commons 
A partir de estos modelos, se asigna a cada estudiante el nivel correspondiente en cada una de las preguntas del cuestionario inicial y final. En la Tabla 3 se muestra el resultado para 10 alumnos que completaron ambos cuestionarios. En general todos los estudiantes han mejorado su nivel en las cuestiones planteadas: 7 de los 10 estudiantes lo han hecho con una diferencia de más de dos niveles en una o más respuestas; y 6 de los 10 estudiantes han mejorado con una diferencia de un nivel en una o más respuestas.

Tabla 3. Seguimiento de cada estudiante.

\begin{tabular}{|c|c|c|c|c|c|c|c|c|}
\hline \multirow[b]{2}{*}{ Estudiante } & \multicolumn{2}{|c|}{ Pregunta 1} & \multicolumn{2}{|c|}{ Pregunta 2} & \multicolumn{2}{|c|}{ Pregunta 3} & \multicolumn{2}{|c|}{ Pregunta 4} \\
\hline & $\cdot \frac{\vec{U}}{\underline{\underline{U}}}$ & $\begin{array}{l}\stackrel{\vec{\sigma}}{\rightleftarrows} \\
\stackrel{\leftarrow}{\Psi}\end{array}$ & $\frac{\overrightarrow{\underline{U}}}{\frac{U}{\underline{S}}}$ & 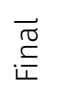 & $\frac{\overrightarrow{\underline{U}}}{\underline{\underline{U}}}$ & 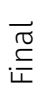 & $\cdot \frac{\vec{U}}{\underline{\underline{U}}}$ & 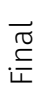 \\
\hline 1 & D & C & C & B & D & B & D & B \\
\hline 2 & C & A & D & B & D & A & B & A \\
\hline 3 & B & A & D & A & D & A & C & A \\
\hline 4 & E & B & D & B & C & A & $E$ & B \\
\hline 5 & C & B & B & A & C & B & $E$ & B \\
\hline 6 & C & B & D & B & D & C & D & C \\
\hline 7 & B & A & C & A & B & A & C & B \\
\hline 8 & C & B & D & A & D & B & C & B \\
\hline 9 & D & C & B & A & D & B & D & A \\
\hline 10 & D & B & B & A & D & C & E & A \\
\hline
\end{tabular}

Los resultados globales del grupo se representaron en forma de escaleras de aprendizaje para cada pregunta. A modo de ejemplo, en la Figura 3 se presenta la escalera realizada para la pregunta 3 del cuestionario. En la misma se refleja el porcentaje de estudiantes en cada nivel del cuestionario inicial (en negro) y final (en marrón), así como

Ciclos de Mejora en el Aula (2020). Experiencias de Innovación Docente de la US Esta obra se distribuye con la licencia Creative Commons 
los principales obstáculos de aprendizaje, que en este caso fueron tres: la referencia al concepto general de "acciones cambiarias", más allá de indicar la posibilidad de plantear una reclamación de cantidad (entre el nivel D y C); el hecho de ser capaz de identificar las acciones cambiarias directa y regreso, y contra quién pueden ejercitarse (entre el nivel $C$ y B); y, por último, el paso más significativo en el proceso de aprendizaje de este extremo del Derecho cambiario, que es identificar no sólo las acciones cambiarias directa y de regreso y contra quién pueden ejercitarse, sino también las acciones extra-cambiarias causal y de enriquecimiento injusto y en qué casos pueden plantearse (obstáculo entre los niveles B y A).

\section{3. ¿Qué acciones judiciales podrían ejercitarse?}

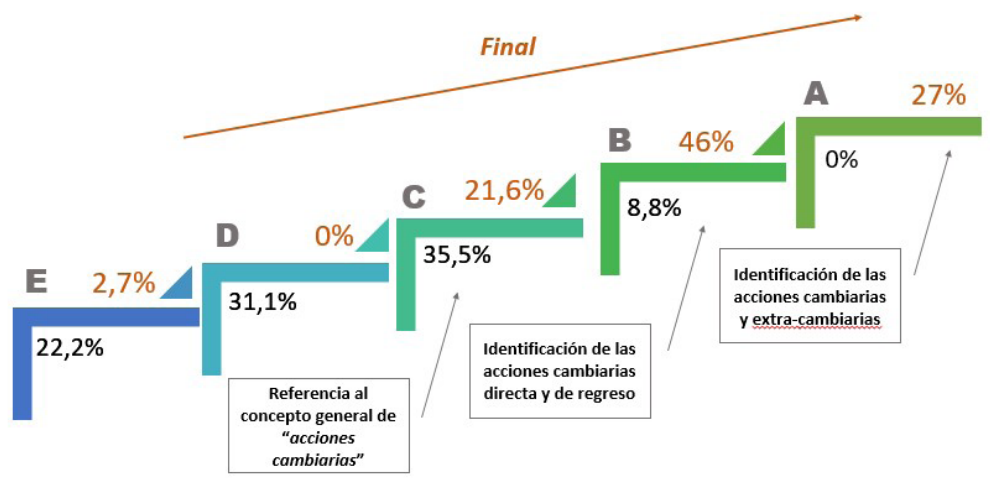

Figura 3. Escalera de aprendizaje para la pregunta 3.

\section{Evaluación del Ciclo de Mejora en el Aula}

Gracias al CGDU he sido consciente de la importancia que tiene conocer en qué punto se encuentran los alumnos en el momento de comenzar en clase con el aprendizaje de nuevos contenidos. Consecuentemente con ello, he podido comprobar que, en mi anterior práctica docente, ni los contenidos ni el modelo metodológico ni la evaluación Ciclos de Mejora en el Aula (2020). Experiencias de Innovación Docente de la US 
estaban en coherencia con el nivel de los alumnos, y tampoco introducía actividades para superar las dificultades que traían de partida. Por ello, me propongo implementar en mi docencia, progresivamente, un sistema (contenidos-metodología-evaluación) no sólo más coherente, sino también más justo con las capacidades de mis estudiantes.

Por último, y como fruto de esta experiencia, los principios didácticos personales que extraigo y que guiarán a partir de ahora mi docencia son los siguientes:

- Tener más presente cuál es el objetivo o fin último de mis clases: más que terminar el programa y todos sus apartados, hacer, dentro de cada bloque, un análisis previo de los contenidos que realmente tienen que saber/ saber hacer/ser, y, a partir de ahí, elaborar un diseño de las sesiones enfocadas en el proceso de aprendizaje del alumno.

- Utilizar mapas de contenidos, dado que con el diseñado he logrado abarcar en el CIMA contenidos de epígrafes del programa que antes desarrollaba de forma independiente, y con un lapso entre sesiones que dificultaban su interconexión y comprensión (García, Porlán y Navarro, 2017).

- Crear experiencias de aprendizaje diversas (Bain, 2007), en las que los alumnos tengan un papel más protagonista (ideas de los estudiantes, problemas prácticos reales, puestas en común).

- Alcanzar un sistema (contenidos-metodología-evaluación) más coherente y justo con las capacidades de mis estudiantes: los cuestionarios inicial y final, así como la observación han sido las dos herramientas que más me han sorprendido en esta experiencia (Rivero y Porlán, 2017).

Ciclos de Mejora en el Aula (2020). Experiencias de Innovación Docente de la US Esta obra se distribuye con la licencia Creative Commons 
Palabras clave: Derecho Mercantil, Grado en Derecho, títulos cambiarios, docencia universitaria, experimentación docente universitaria.

Keywords: Commercial Law, Law Degree, bill of exchage, university teaching, university teaching experimentation.

\section{Referencias bibliográficas}

Bain, K. (2007). Lo que hacen los mejores profesores universitarios. València: Publicaciones de la Universitat de València.

Finkel, D. (2008). Dar clase con la boca cerrada. València: Publicaciones de la Universitat de València.

García, E., Porlán, R., Navarro, E. (2017). Los fines y los contenidos de enseñanza. En R. Porlán (Coord.), Enseñanza universitaria. Cómo mejorarla (pp. 55-72). Madrid: Ediciones Morata.

Jiménez, G. y Díaz, A. (2020). Lecciones de Derecho Mercantil. Madrid: Tecnos.

Pacheco, M. y Barrero, E. (2015). Casos y cuestiones de Derecho Mercantil. Sevilla: Red de Impresión 2013.

Rivero, A., y Porlán, R. (2017). La evaluación en la enseñanza universitaria. En R. Porlán (Coord.), Enseñanza universitaria. Cómo mejorarla (pp. 73-91). Madrid: Morata.

Ciclos de Mejora en el Aula (2020). Experiencias de Innovación Docente de la US Esta obra se distribuye con la licencia Creative Commons 